\title{
Review
}

\section{Probiotics and health: An evidence-based review}

\section{Paolo Aureli ${ }^{\mathrm{a}}$, Lucio Capurso $^{\mathrm{b}}$, Anna Maria Castellazzi $^{\mathrm{c}}$, Mario Clerici $^{\mathrm{d}}$, Marcello Giovannini $^{\mathrm{e}}$, Lorenzo Morellif $^{\mathrm{f}}$, Andrea Poli ${ }^{\mathrm{g}, *}$, Fabrizio Pregliasco ${ }^{\mathrm{h}}$, Filippo Salvini ${ }^{\mathrm{i}}$, Gian Vincenzo Zuccotti ${ }^{1,1}$}

a Microorganisms and Food Technologies Division, Istituto Superiore di Sanità, Rome, Italy

b San Filippo Neri Hospital, Rome, Italy

c Department of Pediatric, University of Pavia, Italy

d Department of Biomedical Sciences and Technology, University of Milan and Don C. Gnocchi Foundation, Milan, Italy

e Italian Society for pediatric Nutrition, Italy

${ }^{\mathrm{f}}$ Institute of Microbiology, Catholic University “Sacro Cuore”, Piacenza, Italy

${ }^{g}$ Nutrition Foundation of Italy, Viale Tunisia 38, 20124 Milan, Italy

h Department of Public Health, Microbiology, and Virology, University of Milan, Italy

i Pediatric Department, University of Milan, San Paolo Hospital, Italy

${ }^{1}$ Department of Pediatrics, University of Milan, Luigi Sacco Hospital, Italy

\section{A R T I C L E I N F O}

\section{Article history:}

Received 15 February 2011

Accepted 15 February 2011

\section{Keywords:}

Microbiota

Probiotics

Immune system

\begin{abstract}
A B S T R A C T
The intestinal microbiota is an ecosystem formed by a variety of ecological niches, made of several bacterial species and a very large amount of strains. The microbiota is in close contact with the intestinal mucosa or epithelial interface which is, after the respiratory area, the largest surface of the body, occupying approximately $250-400 \mathrm{~m}^{2}$. The physiological activities of the microbiota are manifold and are just being unraveled. Based on the observations of the multiple roles played by the microbiota in health and disease, the notion of modifying it with appropriate formulations, i.e. probiotics, is being tested in several settings.

This review summarizes the current knowledge on probiotics and discusses both limitations and acquired evidence to support their use in preventive and therapeutic medicine.
\end{abstract}

(c) 2011 Elsevier Ltd. All rights reserved.

\section{Contents}

1. Introduction

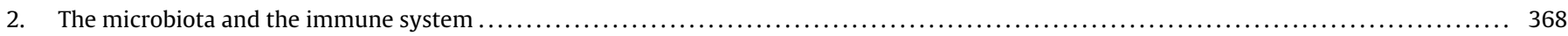

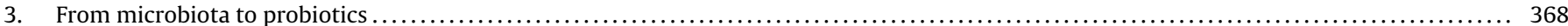

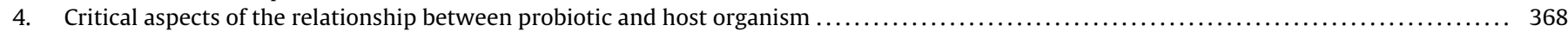

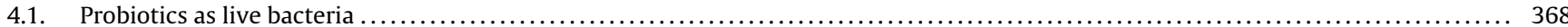

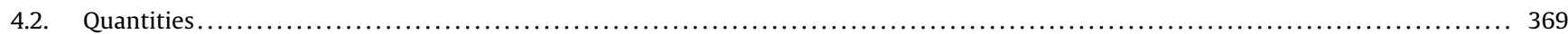

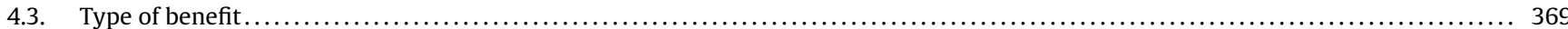

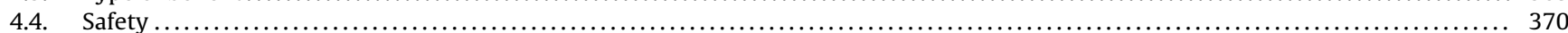

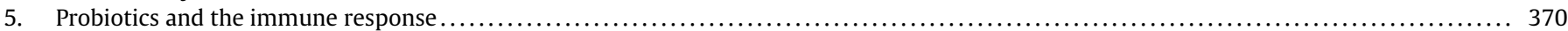

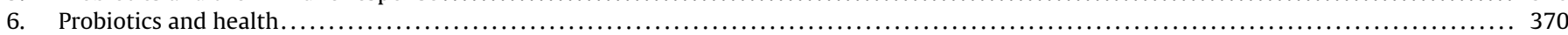

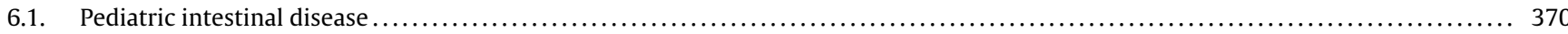

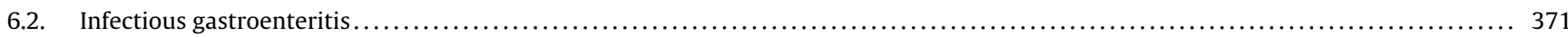

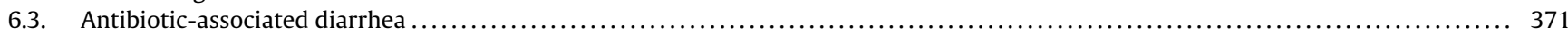

\footnotetext{
* Corresponding author.

E-mail address: poli@nutrition-foundation.it (A. Poli).

1 This article was written collaboratively and the order of authorship is alphabetical only.
} 


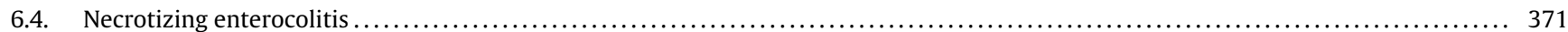

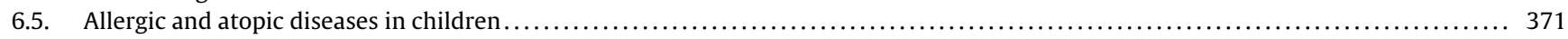

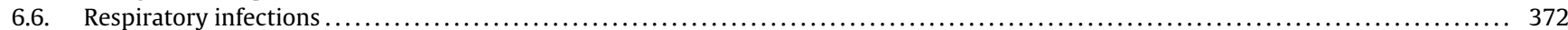

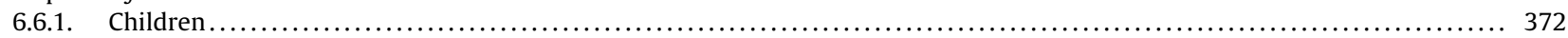

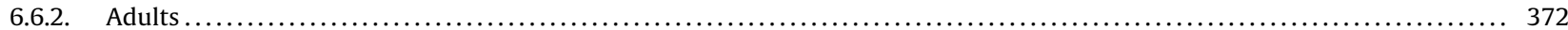

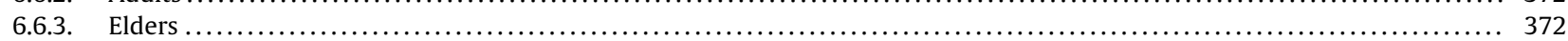

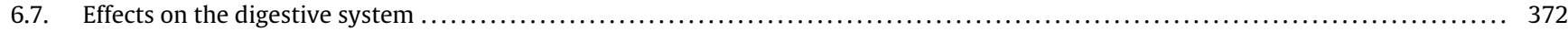

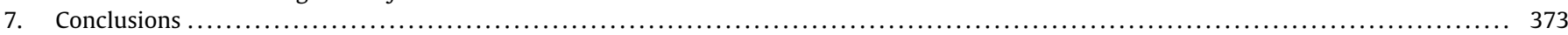

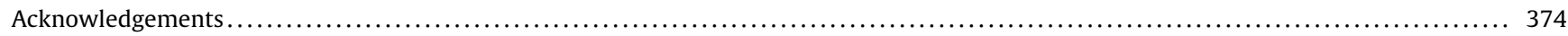

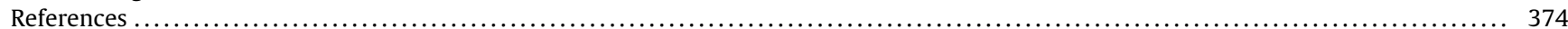

\section{Introduction}

The intestinal microbiota (a term that has now replaced the old denomination of "microflora" $[1,2]$ ) is an ecosystem formed by a variety of ecological niches, made of several bacterial species and a very large amount of strains [3-8]. The microbiota is in close contact with the intestinal mucosa or epithelial interface which is, after the respiratory area, the largest surface of the body, occupying approximately $250-400 \mathrm{~m}^{2}$.

Both microbiota and mucosa, along with mucus, form the so-called mucosal barrier, an important defense system against potentially immunogenic or pathogenic factors present in the lumen. In fact, the epithelial interface separates the lumen containing the microbiota and organic residues of food and secretions (salivary, gastric, pancreatic, biliary, intestinal), from the specific gut-associated lymphoid system (GALT).

The microorganisms constituting the microbiota are unevenly distributed along the digestive tract, as summarized in Table 1. Through their metabolic activities, these organisms play an important role in the use of nutrients ingested with food; they also significantly affect the development and performance of the immune system and other functions [9-12].

The cells that constitute the immune system, responsible for the defensive responses against pathogens, are mostly concentrated in the lymphatic structures that are located in the basement membrane, or lamina propria, of the gastrointestinal tract. Numerous follicular structures and Peyer's patches form part of the GALT, together with $\mathrm{T}$ lymphocytes aggregates, antigen presenting cells (APC), and B lymphocytes, characterized by the production of IgA (secretory antibodies typical of mucosal immunity). IgA are resistant to proteolysis and do not activate the complement; therefore, they play a protective function without pro-inflammatory actions. $\mathrm{T}$ lymphocytes are present either as CD4+ Helper T lymphocytes in their subsets (TH1, TH2, TH17, TH9), or as CD8+ T cytotoxic cells and Regulatory $\mathrm{T}$ (Treg) gd cells.

The microbiota of each individual has a specific "bacteria fingerprint", a profile of its own species which is different from other individuals; nevertheless, there exists a core of at least 57 bacterial species that can be considered common to all humans. The microbial community is typically dominated by two bacterial phyla (divisions), i.e. bacteroidetes and firmicutes, which represent more than $90 \%$ of the phylogenetic groups present in the human gut, at least in its distal part.
The human gut microbiota is currently the focus of very advanced research techniques - including studies on the bacterial genome (microbiome) - whose results are published in prestigious scientific journals [3-8]. Two major projects, based on systematic DNA sequencing of the microbiota, are currently in progress: (a) the Human Microbiome Project (HMP), in the USA and (b) the Metagenomics of the Human Intestine (metaHIT), held in Europe. A report on the latter has been published and confirms the presence of a wide range of bacterial species in the microbiota, i.e. over 1000 in 124 sampled individuals and approximately 160 for each individual at study [13]. A surprising result of the meta-genomics analysis shows $15 \%$ of the sequences defined as coding known or undefined functions, suggesting that the real understanding of the role of intestinal bacterial biomass will still take many years of research and analysis.

There are two main features of the human intestinal microbiota: (1) the ability to adhere to host proteins (collagen, fibrinogen, fibronectin), which confirms a series of data collected over the years by other analytical techniques and that postulates in adherence the prerequisite for a possible persistence of bacterial strains in the gastro-intestinal system; (2) the ability to ferment carbohydrates.

The interaction between microbiota and host organism generates, for both, advantages of different kinds. The main functions of the microbiota bearing positive effects on the host organism are the following: (1) participation in the formation of the intestinal wall (see Box 1); (2) resistance to colonization: in 1916, Nissle [14] demonstrated for the first time the role of human microbiota in conferring resistance to typhoid Salmonella infection and identified in the microbiota, as was later confirmed, the first line of defense against pathogenic bacteria invasion [15]; (3) production of short chain fatty acids, metabolites that play important physiological functions in fermentation (acetic acid for muscles, heart and brain, propionic acid for gluconeogenesis; butyric acid for the enterocyte function) [16]; (4) production of vitamins: especially those of the B group and K [17]; (5) interactions with the mucosal immune system [18,19]; (6) degradation of xenobiotics, with genes capable of synthesizing enzymes having a catabolic activity towards these compounds [5].

It is important to observe that the ability of the microbiota, which depends on its composition, to "extract" calories from a diet $[20,21]$ could explain part of the pathophysiological interpretations of overweight and obesity. Table 2 summarizes some anatomical or

Table 1

Distribution of the microbiota in the digestive system.

\begin{tabular}{|c|c|c|}
\hline Site & Bacterial cells per gram of intestinal contents & Notes \\
\hline Stomach, duodenum & $<10^{3}$ & $\begin{array}{l}\text { Lactobacilli, Streptococci } \mathrm{HCl} \text {, peristalsis and } \\
\text { bile inhibit the adhesion of bacteria and } \\
\text { prevent colonization }\end{array}$ \\
\hline Fasting, ileus, distal ileum & $10^{2}-10^{3}$ & $\begin{array}{l}\text { Lack of information: likely activity of } \\
\text { fermentation of carbohydrates }\end{array}$ \\
\hline Large intestine & $\begin{array}{l}10^{4}-10^{7} \\
10^{10}-10^{12} \text { (prevalence of anaerobes) }\end{array}$ & Body location of most microbiota activities \\
\hline
\end{tabular}


Table 2

Effects of microbiota on host organism.

\begin{tabular}{|c|c|c|}
\hline & GAC (germ-free animal) & MAC (ex-germ-free animal riconventionalized) \\
\hline Intestinal epithelium & Thin & Thickened \\
\hline Kinetics of enterocytes & Slow & Fast \\
\hline Bile acid metabolism & Significant deconjugation & No deconjugation \\
\hline Cholesterol metabolism & No coprostanol & Coprostanol presence \\
\hline SCFA production & Reduced production & Significant production \\
\hline Immunological activity & Reduced & Present \\
\hline
\end{tabular}

\section{Box 1: The defense system of the intestinal mucosa.}

The defense system of the intestinal mucosa can be divided into three main components:

1. pre-epithelial, consisting of mucus, trefoil peptides, and lipids forming a continuous gel in which a fluid rich in bicarbonates that maintain a neutral $\mathrm{pH}$ is secreted;

2. epithelial, composed of cells bound together by tight junctions (a complex of occluding proteins such as zonulin ZO-1, ZO-2, ZO-3, claudins, cingulines, 7H6, occludins, cadherins) that prevent the passage of material between cells: the functionality of tight junctions can be modulated by the expression of these proteins;

3. post-epithelial, formed by the constituents of the lamina propria.

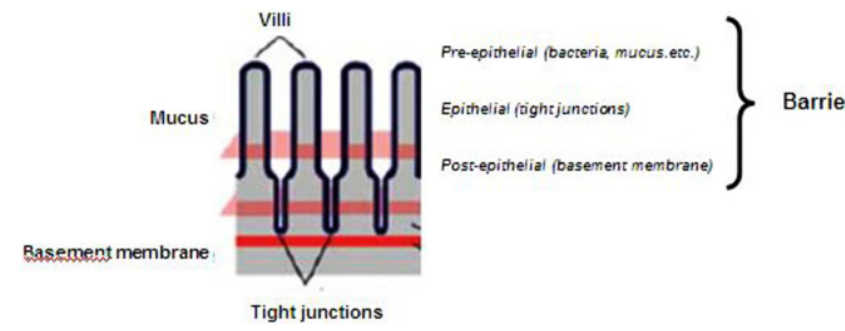

functional aspects of the host organism as linked to the presence and activity of the intestinal microbiota.

\section{The microbiota and the immune system}

The relationships established between microbiota and host organism can be either commensal or symbiotic. The bacteria of the microbiota, as mentioned, are essential in facilitating the absorption of nutrients (for example, by allowing the hydrolysis of some otherwise non-digestible carbohydrates for the body) and in preventing the intestinal colonization by and, thus, the entering the body of pathogenic microorganisms. Therefore, it is vital that the immune system recognizes the components of the microbiota as such and establishes a state of tolerance towards them. The tolerance of the microbiota is mediated by some complementary mechanisms: (1) microbiota bacteria do not express virulence factors, e.g. secondary to chemical modifications of pathogenassociated molecular patterns, antigenic structures recognized by toll-like receptors (TLRs) on the surface of immune system cells or (2) some commensal bacteria are able to suppress inflammatory processes (for example by down-regulation of the activity of NF- $\kappa B$ [22]).

\section{From microbiota to probiotics}

According to the currently international FAO/WHO definition, established by a group of experts convened in 2001 [23], probiotics are: "Live microorganisms which when administered in adequate amounts confer a health benefit on the host". In Italy, the Ministry of Health [24] has defined probiotics as "microorganisms which, once ingested in adequate amounts, have beneficial effects on the organism" essentially resuming the definition of the two UN organizations. It should be emphasized that the FAO/WHO definition does not mention the human origin of the bacterial strain as criteria for the selection and definition of probiotics and, instead, is based on the type of effect caused [25]. This transfer of definition from scientific purpose to regulatory function has led to consider the term "probiotic", which in its original definition implies a health benefit, as a real "health claim" pursuant to Regulation (EC) n.1924/2006; this interpretation, if confirmed, on the one hand will lead to restrictions on the use of the term in foods and supplements, but will probably also allow consumers to immediately identify the strains and the products for which a beneficial effect on health has been demonstrated. From a functional point of view, experimental data suggest that probiotics may contribute to strengthening the activities of the intestinal mucosal barrier, particularly by influencing intestinal epithelial cells (IEC) and macrophages.

A recent review by Thomas et al. [26] has drawn attention to the most important mechanisms of action and to the diversity of each strain at the level of IEC and macrophages. A list of the possible mechanisms of modulation of probiotics on the signaling systems in intestinal epithelial cells (IEC) and macrophages can be found therein [26]. The most important mechanisms underlying these actions are summarized in Box 2 .

\section{Critical aspects of the relationship between probiotic and host organism}

The main practical aspects of the relationship between probiotics and host organisms - defined to allow a rational use of probiotics and improve the physiological functions of the host - are the following: (1) importance of live bacteria administration; functional characterization and identification of bacteria; (2) amount of bacteria to be administered (depending on the strain employed, in combination with other strains of same or different species, on the selected food matrix and industrial form of presentation) and counting techniques; ( 3 ) benefits for the host and their definition; (4) safety of use (also in the light of the two FAO/WHO documents of 2001 and 2002 and of the concept of QPS for the safety assessment of bacteria, recently introduced by EFSA).

\subsection{Probiotics as live bacteria}

The tradition that dates back to Metchnikoff includes both the use of a food matrix fermented by a "beneficial" bacterium and a "concentrated" bacterial supplementation of diet. Both scenarios provide consumers with live bacteria that are able to pass the gastric and ileal environments and, then, to reproduce themselves in the large intestine. This concept, ecological in nature, supports the use of live bacteria able to settle among other live bacteria, i.e. the microbiota and exercise functions involving metabolic activity. The studies supporting the efficacy of live bacteria are numerous; conversely, there are few and conflicting results on the effects of the same strain administered in either viable or non-viable forms. 
Box 2: Mechanisms of interaction between probiotics and intestinal epithelial cells.

- Induction of the synthesis of cytoprotective heat shock proteins

Intestinal epithelial cells (IEC), when in contact with heat, osmotic, oxidative, or other stresses, activate a system of "stress tolerance" based on the induction of heat shock proteins (hsp). Heat shock proteins in the gut include $h s p 25$ (that stabilizes actin) and $h s p 72$ (that prevents cell denaturation). These mechanisms help maintaining efficient tight junctions between IEC, thus promoting the function of the mucosal barrier [119]. Probiotics in the gut induce the production of cytoprotective heat shock proteins [120].

- Modulation of inflammatory signaling systems in IEC

IEC are equipped with signaling systems to activate the immune response and face a variety of stimuli. NFKB represents the main system, which is present in the cytoplasm in its inactive form, bound to inhibitory molecules of the І $B$ family. In the presence of pro-inflammatory stimuli, ІКB phosphorylates, detaches from NFKB and, thus, allows NFKB itself to migrate from the cytoplasm to the nucleus, activating the transcription of specific genes [121]. Some probiotics modulate the degradation of $\mathrm{I} \kappa \mathrm{B} \alpha$ whereas others stimulate NFKB to increase the secretion of specific cytokines [122]. Lactobacillus plantarum inhibits the activity of NFKB and the degradation of IKB in vitro [123]. Another molecular target modulated by probiotics is PPAR $\gamma$, a nuclear receptor that can regulate the level of intestinal inflammation and, in particular, may play a role in alleviating some intestinal inflammatory diseases by inhibiting the activity of NFKB (PPAR $\gamma$ is, indeed, present in small amounts in the IEC of patients with inflammatory bowel disease, or IBD) [124,125]. Treatment with specific strains of probiotics can increase the expression of PPAR $\gamma$ and, thereby, improve inflammation in patients with IBD $[126,127]$.

- Regulation of apoptosis

Some probiotics may regulate apoptosis of IEC. Lactobacillus rhamnosus GG ATCC 53103 can activate a protein with anti-apoptotic action and inhibit a protein with pro-apoptotic action in IEC stimulated with various cytokines (TNF- $\alpha$, IL$1 \alpha-\beta$ or IFN $\gamma$ ). Some experiments show that LGG activates the production of two proteins, p75 and p40, which promote cell proliferation and activate Akt anti-apoptotic protein [128]. The ability of probiotics to regulate apoptosis may also represent a useful strategy for the control of intestinal infections [129].

- Modulation of the signaling systems of macrophages

At the gut level, probiotics modulate different signaling systems of macrophages, with effects on mucosal immunity.

Therefore, due to well-established definitions and for the sake of better consumer information, the term probiotic is to be reserved for products containing living and vital cells.

The identification of the strain is necessary, both for safety reasons and to prove their beneficial action. Evidence, in fact, indicates that different strains of the same species may exert different effects on the host (Table 3). In brief, species must be identified by determining the DNA nucleotide sequence coding the 16S RNA, while the strain should be characterized by macro-restriction profile of the chromosome, as determined by pulsed field electrophoresis (PFGE). The filing in an International collection of strains is also recommended. Strains of the same species can exert different and sometimes opposite actions. The differences of actions between the various strains are well-established in the scientific literature, as cited in the FAO/WHO document: "data obtained with one specific probiotic food cannot be extrapolated to other foods containing that particular probiotic strain or to other probiotic microorganisms" [23], as well as in the AFSSA (Agencie Française de Sécurité Sanitaire des Aliments) document: "The quantity of probiotics passing live through the gut depends on the strain, the dose ingested, factors related to the host and the vector food" [27].

The analytical methods are well established and outlined in a series of documents: (a) 2001 FAO/WHO report [23]; (b) Italian Ministry of Health guidelines for 2005 [24]; (c) EFSA opinions issued between 2009 and 2010 .

\subsection{Quantities}

Little is known about the optimal amount of live probiotic bacteria to be administered; this quantity is not easy to determine: it is strain-specific and it probably depends on the type of benefit sought for with the administration of probiotics (different functional effects may require different amounts of live probiotics). Of course, the overall amount cannot be low, if the aim is to markedly influence the composition of the microbiota of the host. It should be emphasized that, in case of microbial associations, each species in "competition" with a functional action must be provided in appropriate amounts.

In the absence of specific dose-response studies, however, some points reported in the AFSSA paper [27] are worth reiterating: (1) "The dose of probiotics ingested is an important factor to obtain high concentrations in the various compartments of the gastrointestinal tract"; (2) "It is often said that probiotic concentrations must be greater than or equal to $10^{6} \mathrm{CFU} / \mathrm{mL}$ in the small intestine (ileum) and $10^{8} \mathrm{CFU} / \mathrm{g}$ in the colon, but the scientific basis for these statements is relatively weak"; (3) "The concentrations in the colon have been proposed because they correspond to less than $1 / 1000$ of the autochthonous flora present (which it could be reasonably expected has more chance of being active than flora present at even lower levels)". It is also necessary to remember that there is no scientific evidence proving a synergistic effect of two or more strains of bacteria in determining a functional or metabolic impact in humans. Yet, there is theoretical support to the notion that the intake of two or more bacterial species may have additional or synergistic functional effects; moreover some studies, albeit limited, seem to suggest a negative cross-effect.

\subsection{Type of benefit}

Probiotics can improve - within physiological limits - some functions of the digestive system, such as stool frequency or subjective characteristics. The consumption of probiotics may also be useful in reducing the risk of specific diseases, mitigating both objective and subjective symptoms, if manifest. Experimentally, it should be noted that the effects of probiotics have been observed mainly by studying groups of diseased subjects affected. This choice was and is based on purely methodological reasons: it is not easy to record significant positive effects of probiotics in the absence of functional abnormalities, as in the case of healthy populations.

This approach has allowed obtaining encouraging results, but it has also underlined the problem of data transferability to the part of the population representing habitual probiotics consumers and defined by FAO/WHO as: "otherwise healthy people".

We believe that, in many situations such as those of predominantly subjective symptoms (for which there is a sort of continuum between normal and clinical pathological states), the possibility to transfer to healthy "pouchitis-symptomatic" subjects data collected in patients with more complex clinical pictures dramatically improves the possibility to prove significant functional effects of probiotics. The observed effects are usually related to the presence of probiotics in the intestinal tract, ensured only by protracted administration. Long-term studies should complement the many 
Table 3

Difference in probiotic action between strains of the same species. Examples refer to the action on host organism only and not to viability and persistence.

\begin{tabular}{|c|c|c|}
\hline Species/strain & Action & Reference \\
\hline Bifidobacterium longum W11 & Low induction of IL10 and high induction of Th1 & {$[101]$} \\
\hline Bifidobacterium longum NCIMB 8809 and Bifidobacterium longum BIF53 & High induction of IL10 low induction of Th1 & [101] \\
\hline Lactobacillus rhamnosus GG and Lactobacillus rhamnosus 1970-2 & Difference in ability of colonization in vivo & {$[102]$} \\
\hline Lactobacillus crispatus M247 e Lactobacillus crispatus MU5 & Difference in ability of colonization in vivo & {$[103]$} \\
\hline
\end{tabular}

those already exist and that describe the effects of limited-duration interventions.

\subsection{Safety}

The safety assessment of microbial species proposed as probiotics has always been a pillar of regulatory authorities. The distribution of microbial species has, for years, been subjected to the verification of a long tradition of safe consumption or to a caseby-case evaluation that followed, in the EU, the criteria regarding novel foods, feed (zootechnical) additives, or drugs, according to their conditions of use.

In the food sector, the introduction of new rules has also led to the adoption of new instruments for the evaluation of probiotics, based on the so-called "Qualified Presumption of Safety (QPS)" [28]. Consequently, every microbial strain for which an identity has been unequivocally established and classified in a QPS group, i.e. a group that does not raise concern from the point of view of safety, is only subjected to the verification of the absence of specific "qualifications" that may cause concern for public health before the final approval of its safety standards of use. At present, the characterization of a specific strain is based on the absence of resistance to antibiotics of clinical and veterinary interest as well as of virulence factors [29].

In reality, resistance to antibiotics is not in itself a major safety issue, as different microorganisms are inherently indifferent to the activity of antibiotics, but it becomes a problem when it is accompanied by a horizontal transfer of genetic determinants [30]. For this reason, the Scientific Committee on Animal Nutrition of the EU (SCAN) and the EFSA Panel on additives, products and substances used in animal feed (FEEDAP) require the absence of transferable antibiotic resistant genes as a prerequisite for approval of a microorganism. Although there are no legally mandatory criteria for probiotics in food supplements for humans, the verification of the absence of transferable resistance is recommended for safety assessment at EU level and by, e.g. the Italian Ministry of Health.

\section{Probiotics and the immune response}

A series of recent observations made it possible to clarify the mechanisms of immune responses occurring in the intestine. Many of these mechanisms can be influenced by specific strains of probiotics. In the intestinal lamina propria, B cells are differentiated into plasma cells and secrete dimeric IgA antibodies that, on the basolateral surface of intestinal epithelial cells, bind to a specific receptor transporting them to the apical surface, where they are released into the intestinal lumen. The secretory IgA are important elements of mucosal immunity and participate in the protection of the host by binding a wide variety of dietary, bacterial, viral, and fungal antigens.

The hypothesis that probiotics might influence immunity by altering specific immune parameters, thus playing beneficial roles in human diseases is of great interest. In fact: (1) probiotics modulate and stabilize the composition of the microbiota and, therefore, may have immunomodulatory effects; (2) some probiotics are able to inhibit the inflammatory response of the intestinal immune system through inhibition of NF- $\mathrm{KB}$ activation or in combination with an anti-apoptotic action on intestinal epithelial cells [31,32]; (3) some probiotics are able to increase the activity of Natural Killer (NK) cells [33,34], which are first line of defense as they can perform cytotoxic activities independent from prior sensitization to antigens; (4) some probiotics increase the secretion of mucus [22]; (5) some probiotics have a direct immunomodulatory action: after being captured in the Peyer's patches, they can induce the secretion of cytokines and the expression of co-stimulatory molecules by antigen presenting cells (APC) [35]; (6) some strains of lactobacilli induce dendritic cells (DC) maturation [36]. DC can, through their particular cytostructure, pass through the layer of epithelial cells and capture antigens directly from the lumen. This characteristic of DC, combined with their ability to guide $T$ cells response and thus stimulate the secretion of IL-10 and IL-12, underlines their role as links between microbiota, innate immunity, and adaptive immunity. With a targeted use of specific probiotic strains, it is possible to induce an immune stimulant type of response on both $B$ (increase of humoral immunity) and T lymphocytes (increase of cell-mediated immunity) and on the phagocytic component, particularly on polymorphonuclear cells $[37,38]$. The ability to stimulate responses of this type is useful in very specific clinical circumstances, for example for immunoprophylaxis of upper respiratory tract infections during winter or, in addition to influenza vaccination, to increase antibody response to vaccine or, more generally, to increase nonspecific immunity surveillance to pathogens of different nature $[39,40]$.

Recent studies have provided positive results on the effects of probiotics on the respiratory system, especially with regard to preventing and reducing the severity of respiratory infections due to an increase in IgA-secreting cells in the bronchial mucosa [41]. Positive effects were also found in regular smokers, usually affected by reduced NK cell activity [42].

Children also represent a main target of studies that investigate the effects of probiotics on human health, because of the importance of limiting the spread of diseases especially during wintertime, reducing missed days at school, and decreasing the need of antibiotics [43-45].

\section{Probiotics and health}

\subsection{Pediatric intestinal disease}

During the first weeks of life the innate defense mechanisms are more important than the acquired ones, because even healthy infants are immunologically naïve, not having being exposed - intra uterus - to nearly any antigen. In this early period of life, colostrum and breast milk can increase the resistance to enteric infections in newborns; the mechanisms for this increased resistance to infection are both passive (due to the passing through the milk of anti-microbial factors) and active, through the promotion of the development of specific immune functions, in nature. The neonatal immune system faces two major challenges: on the one hand it has to actively respond to the antigens of pathogenic bacteria, and on the other hand it must "tolerate" the antigens of both dietary and non-pathogenic bacteria. The regulation of these responses of tolerance and of active response is important for good health: the loss of these properties may lead to recurrent infections, inflamma- 
tory and autoimmune diseases, and allergies. The education of the immune system in the first moments of life is critical for minimizing the onset of these immune-mediated disorders. Bacterial flora antigens, transmitted from mother to infant and which colonize the intestine already $48 \mathrm{~h}$ after birth (Escherichia coli and Streptococci) are fundamental for this "education" process. Diet also affects the microbiota of the newborn: breastfed babies have a predominant colonization with $E$. coli and Streptococci bifidobacteria, while those fed with formula milk have microbiotas with predominance of bifidobacteria, bacteroidi, clostridia and other enterobacteria. The gradual establishment of the flora from the early hours of life allows modulating the immune response in favor of the acquisition of oral tolerance $[46,47]$, defined as "specific immunological hyporesponse to a previous exposure to mucosal antigen". As mentioned, the production of secretory $\operatorname{IgA}$ is one of the basic immunological mechanisms in the establishment of oral tolerance, especially during the peri-natal period, but also in the protection from pathogens. Breast milk contains secretory IgA, which may be useful for this purpose. Conversely, infants who are fed with formula milk supplemented with probiotic bacteria may experience promotion of the natural production of this immunoglobulin. Supplementation with probiotics is generally considered safe because they are identical to the microorganisms present in vaginal flora and in the human gastrointestinal tract. In recent years, clinical trials in children have multiplied and have assessed the effects of probiotics in the prevention and control of both acute and chronic gastrointestinal disorders, in addition to non-intestinal diseases such as atopy [48]. The interpretation of the results is often controversial, because studies differ in terms of microorganisms used, studied population, assessment of the doses, and frequency of administration. Hereafter, we present a critical evaluation of the available evidence regarding the use of probiotics in children, in specific para-physiological or pathological conditions.

\subsection{Infectious gastroenteritis}

Most of the recent studies have demonstrated the efficacy of specific probiotics in reducing the symptoms in pediatric populations affected by infectious gastroenteritis [49-52]. Probiotics reduce the duration of infectious diarrhea by 0.7 days as well as the frequency of diarrheal episodes already in the first hours [53]. According to the latest scientific evidence, their consumption is, therefore, recommended in case of acute gastroenteritis starting from the onset of symptoms. In general, probiotics should be administered for at least 5 days and, in any case, for the duration of hospitalization, in one or two daily doses. The effect is most evident in cases of early treatment of rotavirus infection with oral rehydration therapy associated with Lactobacillus GG [54-57]. This probiotic is able to decrease the excretion of rotavirus in the stool [58], helping to reduce the spread of the virus, in turn improving the effectiveness of preventive strategies both in communities and during hospitalization. Yet, definitive conclusions cannot be drawn based on the available results [59-61]. The effectiveness of treatment with probiotics is demonstrated in mild- to moderateseverity rotavirus gastroenteritis, while the results obtained in the treatment of rotavirus negative forms and, especially, in bacterial infections are inconclusive [54,61]. It has been hypothesized that the ineffectiveness of LGG in bacterial diarrhea is due to the ability of bacteria to produce mucinases that neutralize the effects of probiotics [62]. Conversely, a 2005 study has demonstrated the effectiveness of Lactobacillus paracasei ST1 in non-rotavirus gastroenteritis [63]. Data confirming the effectiveness of supplementation with probiotics in the treatment of gastroenteritis in children have also been analyzed in a recent review [64], also focusing on strain-specificity; in particular, probiotics that have shown more promising results are Lactobacillus casei subsp. rhamnosus GG,
Lactobacillus delbrueckii subsp. bulgaricus, Lactobacillus acidophilus, Streptococcus thermophilus, and Bifidobacterium bifidum.

\subsection{Antibiotic-associated diarrhea}

The incidence of antibiotic-associated diarrhea (AAD) ranges between $5 \%$ and 30\% [57]. Most antibiotics may induce, during their use, diarrhea: the risk is greater in case of aminopenicillin therapies, aminopenicillin combined with clavulanic acid, cephalosporins, and clindamycin [65]. Recent meta-analyses reported a significant reduction of $A A D$ cases when antibiotic therapy is associated with prior probiotic treatment [65-67]. Saccharomyces boulardii appears to be the most effective microorganism; however, LGG has also proven to be effective in children $[68,69]$. S. boulardii, for which there is a risk of hematogenous dissemination in immunocompromised patients, was effective in inhibiting the recurrence of episodes of Clostridium difficile infection [70]. Although not all studies have confirmed the effectiveness of probiotics treatment in the prevention of AAD, a 2009 review has shown that effectiveness is mainly related to the strain used [71]; the studies have also confirmed that there is sufficient clinical evidence to support the use of Lactobacillus rhamnosus GG and S. boulardii strains in the treatment of antibiotic-associated diarrhea [72].

\subsection{Necrotizing enterocolitis}

Necrotizing enterocolitis (NEC) is a major cause of morbidity and mortality in premature infants; the etiology of this disease has not yet been fully clarified. Risk factors have been identified such as prematurity, enteral feeding, and bacterial colonization, which would cause the exaggerated inflammatory response responsible for ischemic necrosis of the intestine. Based on observations in animal models, some studies evaluated the effects of probiotics supplementation on the incidence of NEC in newborns. A recent review [73] examined the results of 11 studies, showing that the risk of NEC and death in the population treated with probiotics is lower and confirming significant benefits of a supplementation with probiotics in premature and very-low birth weight infants. This meta-analysis concludes that, due to the important effects achieved, the statistically significant results, and the recorded findings, further randomized trials placebo-controlled are not necessary.

\subsection{Allergic and atopic diseases in children}

In recent years, industrialized countries have seen a significant increase of autoimmune and allergic diseases. The factors responsible for this increase are likely to be impaired maturation of the immune function in early life - which would involve a minor TH2/TH1 switch for low or no contact with infectious agents (hygiene theory) - and altered microbial flora that enables the persistence of cytokines derived from TH2 (IL4, IL5, IL13), dominant at birth, and does not allow the shift towards a predominant TH1 response, with production of IL12 and IFN $\gamma$.

This hypothesis is supported by the observations of changes in the intestinal flora of atopic children, with a prevalence of clostridia [74,75]. In 2007, the first study was published postulating the role of probiotics in the recurrence of allergic respiratory symptoms in children. This study aimed at assessing whether the daily, longterm (12 months) consumption of a fermented milk containing L. casei DN-114 001 probiotic (with immune-modulating activity) could improve human health and modify the immunological profile of pre-school age children with allergic symptoms to inhalants [76]. This was a multicentre, prospective, randomized, doubleblind study, with 187 patients (119 with asthma and 131 with rhinitis, 63 with both symptoms) of both sexes and aged between 
2 and 5 years, followed by eight hospitals in Milan (Italy) and its province. The study showed that supplementation with probiotics reduces by $33 \%$ the recurrence of yearly rhinitis, with a median (IQR) of 2 episodes (1-5) vs. 3(0-8); the incidence of allergic rhinitis was two times lower in children treated with probiotics in the second quarter of supplementation [OR $(95 \% \mathrm{CI})$ ] of 0.39 (from 0.19 to $0.82, p<0.01)$. A genetic analysis of the composition of the intestinal microbial flora was performed on a subgroup of 45 patients, showing a high prevalence of probiotic flora in the gut and, in particular, the presence of numerous $L$. casei DN-114001 colonies in patients receiving the intervention as compared to the control group: gut colonization by probiotics persisted after 6 and 12 months in almost all subjects. Numerous studies have shown promising results on the effectiveness of probiotics in reducing the incidence of allergic reactions [77-80].

Unfortunately, the enormous heterogeneity of studies, strains, duration of therapy and doses used, does not allow drawing a univocal interpretation. The most recent reviews $[81,82]$ do not conclude on the efficacy of probiotics in the treatment or prevention of major allergic diseases. The most promising data only concern the prevention of atopic eczema, although not all studies agree with these results. Indeed, two recent reviews on the use of probiotics in the treatment [83] and prevention [84] of atopic dermatitis affirm that, according to the available studies, there is insufficient evidence to support probiotic supplementation for atopic dermatitis.

\subsection{Respiratory infections}

As mentioned, all probiotics induce an immune response, whose characteristics are related to the strain or the combination of bacteria that have been used. Recent studies have shown positive effects of probiotics on the respiratory system, especially in preventing and reducing the severity of respiratory infections, due to an increase in IgA-secreting cells in the bronchial mucosa [41]. The role of malnutrition and deficiency of some micronutrients and vitamins has also been demonstrated in the process of viral pathogens cell entry and replication [85-87]. The preventive use of supplements containing substances active on the immune system plays an important role both before vaccination and as adjuvant in vaccines, to increase antibodies in the elderly and debilitated subjects $[88,89]$.

Hereafter, we present the results of studies performed on different target populations aimed at investigating the effects of probiotics on infectious diseases of the respiratory system.

\subsubsection{Children}

A randomized, double-blind, placebo-controlled trial was performed to determine whether probiotics may reduce the risk of infections in infants. The children involved in the research were younger than 2 months of age and were daily provided with milk containing L. rhamnosus GG and Bifidobacterium lactis Bb-12, or placebo milk, administered until 12 months of age. The results suggest that probiotics may represent a mean to reduce the risk of early acute otitis media and the use of antibiotics for recurrent respiratory infections during the first year of life [90]. Similar results have emerged in a study performed on a target population of 326 children aged between 3 and 5 years, showing more than $65 \%$ decrease in the incidence of antibiotic use and $25 \%$ reduction in school missed days among children treated with probiotics [91].

\subsubsection{Adults}

A randomized double-blind, placebo-controlled trial assessed whether the consumption for 3 months of Lactobacillus gasser PA 16/8, Bifidobacterium longum SP 07/3, B. bifidum MF 20/5, had impacts on symptoms severity, incidence and duration of common cold. For two winter/spring seasons, 479 adults were daily treated with vitamins and minerals enriched or not with probiotics. The results indicate a reduction in the duration of episodes of common cold of at least 2 days and a decrease in the severity of symptoms among subjects receiving probiotics if compared to the randomized placebo-control group [92]. Similar conclusions were obtained in a study that assessed the effect of long-term intake of probiotics on the same pathology [93]. Another, double-blind, randomized, placebo-controlled trial, performed on 237, 234, and 250 healthy adults investigated, in three winter seasons, the efficacy of different probiotics in restoring and maintaining intestinal balance and the potential protection from respiratory tract infections [94]. The experimental protocol consisted of three phases: (1) in the first phase, an active formulation (A) was tested that contained three types of probiotics (L. plantarum, L. rhamnosus and B. lactis) and fructo-oligosaccharides (FOS), compared to placebo; (2) in the second phase, the same formula was compared to a similar preparation enriched with lactoferrin (B) and to placebo; (3) the third phase compared two symbiotic formulations, each containing probiotics and FOS (C) or galacto-oligosaccharides (GOS, D) with placebo. The average duration of acute respiratory infections improved with respect to ILI (influenza-like illness) and URTI (upper respiratory tract infections) in steps 1 and 2 of the study, while the incidence of cold and cough decreased in phase 3 . Similar results emerge from a systematic review of clinical evidence obtained in 14 research trials (RCT) on the use of probiotics in preventing respiratory tract infections (RTI). The reduction in the severity of symptoms related to RTI was recorded in five out of six studies; in three studies out of nine the clinical course was reduced. Probiotics, therefore, have a beneficial effect on the severity and duration of RTI symptoms, although not reducing their incidence [95].

\subsubsection{Elders}

Two multicentre, randomized, controlled, double-blind studies were conducted in two successive vaccine seasons (pilot study and control). 86 and 222 elderly volunteers consumed, respectively, a fermented milk drink containing $L$. casei DN-114 001, a fermented yogurt or a control unfermented dairy product, twice a day for a period of 7 or 13 weeks. Vaccination took place after 4 weeks. The study showed that probiotics improve antibody responses to influenza vaccination in individuals over 70 years [96]. L. case DN-114001 was also evaluated in a multicentre, double-blind, controlled study on 1.072 elderly, to assess the resistance to respiratory infections. The product containing probiotics, well tolerated, induced a reduction in the duration of respiratory infections, especially URTI and nasopharyngitis [97].

\subsection{Effects on the digestive system}

Many of the investigated effects of probiotics refer to the digestive system. These effects relate to both paraphysiological conditions, e.g. constipation and to situations of illness. A review has recently been published on the effect of probiotic strains on constipation [98]: five clinical studies placebo-controlled were taken into consideration on a total of 377 subjects. The results show that favorable effects on stool frequency and stool consistency were obtained in adults with B. lactis DN-173 010, L. casei and E. coli Nissl 1917 probiotic strains. Some strains have led to a reduction in the perception of bloating (reported by patients before and after treatment). In children, the L. rhamnosus Lcr35 strain showed positive effects although not statistically significant (due to the low number of subjects involved) while the L. rhamnosus GG strain had no impact if compared to placebo. In 2008 another placebo-controlled study was conducted in children with chronic functional constipation, treated for 8 weeks with probiotics (L. reuteri DSM 17938) or placebo. In this case, a significant improvement was observed, 
Table 4

Effects of different strains on some gastrointestinal pathologies.

\begin{tabular}{|c|c|c|c|}
\hline Disorder & Strain & Dose & Ref. \\
\hline Treatment of acute infectious diarrhea in children & $\begin{array}{l}\text { L. rhamnosus GG } \\
\text { L. reuteri ATCC } 55730 \\
\text { S. cerevisiae (boulardii) }\end{array}$ & $\begin{array}{l}10^{10}-10^{11} \text { ufc } \\
10^{10}-10^{11} \text { ufc } \times 2 / d \\
10^{9} \text { ufc } \times 3 / d\end{array}$ & $\begin{array}{l}{[104]} \\
{[104]} \\
{[104]}\end{array}$ \\
\hline Treatment of acute infectious diarrhea in adults & Enterococcus faecium LAB SF68 & $10^{8}$ ufc $\times 3 / \mathrm{d}$ & [104] \\
\hline Prevention of antibiotic-associated diarrhea & $\begin{array}{l}\text { S. cerevisiae (boulardii) } \\
\text { L. rhamnosus GG } \\
\text { B. lactis Bb12+S. thermophilus } \\
\text { Enterococcus faecium LAB SF68 } \\
\text { S. cerevisiae (boulardii) } \\
\text { L. rhamnosus GG } \\
\text { L. casei DN-114 } 001 \text { in fermented milk with L. bulgaricus +S. thermophilus } \\
\text { B. clausii } \\
\text { L. acidophilus CL1285 + L. casei }\end{array}$ & $\begin{array}{l}10^{9} \text { ufc } \times 2 / \mathrm{d} \\
10^{10} \text { ufc } \times 1-2 / \mathrm{d} \\
10^{7}+106 \text { ufc } / \mathrm{g} \text { formula } \\
10^{8} \text { ufc } \times 2 / \mathrm{d} \\
1 \mathrm{~g} \text { or } 3 \times 10^{10} \text { ufc } \times 1 / \mathrm{d} \\
10^{10}-10^{11} \text { ufc } \times 2 / \mathrm{d} \\
10^{10} \text { ufc } \times 2 / \mathrm{d} \\
2 \times 10^{9} \text { spores } \times 3 / \mathrm{d} \\
5 \times 10^{10} \text { ufc } \times 1 / \mathrm{d}\end{array}$ & $\begin{array}{l}{[105]} \\
{[105]} \\
{[105]} \\
{[106]} \\
{[107]} \\
{[108]}\end{array}$ \\
\hline $\begin{array}{l}\text { Prevention of rotavirus nosocomial infection in } \\
\text { children }\end{array}$ & $\begin{array}{l}\text { L. rhamnosus GG } \\
\text { B. lactis Bb12+S. thermophilus } \\
\text { B. lactis Bb12 } \\
\text { L. reuteri ATCC } 55730\end{array}$ & $\begin{array}{l}10^{10}-10^{11} \text { ufc } \times 2 / \mathrm{d} \\
10^{8}+10^{7} \text { ufc } / \mathrm{g} \text { formula } \\
10^{9} \text { ufc } \times 2 / \mathrm{d} \\
10^{9} \text { ufc } \times 2 / \mathrm{d}\end{array}$ & {$[105]$} \\
\hline Prevention of $\mathrm{C}$. difficile infection in adults & $\begin{array}{l}\text { L. casei DN-114 } 001 \text { in fermented milk with L. bulgaricus }+ \text { S. thermophilus } \\
\text { S. cerevisiae (boulardii) }\end{array}$ & $\begin{array}{l}10^{10} \text { ufc } \times 2 / d \\
2 \times 10^{10} \text { ufc } \times 1 / d \\
2 \times 10^{10} \text { ufc } \times 1 / d\end{array}$ & $\begin{array}{l}{[106]} \\
{[105]}\end{array}$ \\
\hline $\begin{array}{l}\text { Adjuvant in therapies for Helicobacter pylori } \\
\text { eradication }\end{array}$ & $\begin{array}{l}\text { L. rhamnosus GG } \\
\text { B. clausii } \\
\text { S. cerevisiae (boulardii) } \\
\text { L. casei DN-114 } 001 \text { in fermented milk with L. bulgaricus +S. thermophiles }\end{array}$ & $\begin{array}{l}6 \times 10^{9} \text { ufc } \times 2 / \mathrm{d} \\
2 \times 10^{9} \text { spores } \times 3 / \mathrm{d} \\
1 \mathrm{~g} \text { or } 5 \times 10^{9} \text { ufc } \times \text { d } \\
10^{10} \mathrm{CFU} \times 2 / \mathrm{d}\end{array}$ & $\begin{array}{l}{[109]} \\
{[109]} \\
{[109]} \\
{[110]}\end{array}$ \\
\hline Reduction irritable bowel syndrome symptoms & $\begin{array}{l}\text { B. infantis } 35624 \\
\text { L. rhamnosus GG } \\
\text { B. longum, B. infantis, B. breve, L. acidophilus, L. casei, L. delbrueckii subsp. } \\
\text { bulgaricus, L. plantarum, S. salivarius subsp. thermophilus } \\
\text { L. rhamnosus GG, L. rhamnosus LC705, B. breve Bb99 and P. freudenreichii } \\
\text { subsp. shermanii JS } \\
\text { B. animalis DN-173 } 010 \text { in fermented milk with L. bulgaricus }+S \text {. } \\
\text { thermophilus }\end{array}$ & $\begin{array}{l}10^{8} \text { ufc } \times 1 / \mathrm{d} \\
6 \times 10^{9} \text { ufc } \times 2 / \mathrm{d} \\
4.5 \times 10^{11} \text { ufc } \times 2 / \mathrm{d} \\
10^{10} \mathrm{ufc} \times 1 / \mathrm{d} \\
10^{10} \mathrm{CFU} \times 2 / \mathrm{d}\end{array}$ & $\begin{array}{l}{[111]} \\
{[112]} \\
{[113]} \\
{[114]} \\
{[115]}\end{array}$ \\
\hline Remission of ulcerative colitis & E. coli Nissle 1917 & $5 \times 10^{10} \times 2 / d$ & [116] \\
\hline Remission of pouchitis & $\begin{array}{l}\text { B. longum, B. infantis, B. breve, L. acidophilus, } \text { L. casei, L. delbrueckii subsp. } \\
\text { bulgaricus, L. plantarum, S. salivarius subsp thermophilus }\end{array}$ & $4.5 \times 10^{11}$ ufc $\times 2 / d$ & [117] \\
\hline Prevention of necrotizing enterocolitis & $\begin{array}{l}\text { B. infantis, S. salivarius subsp. thermophilus, B. bifidum } \\
\text { L. acidophilus + B. infantis }\end{array}$ & $\begin{array}{l}3.5 \times 10^{8} \text { ufc per } \\
\text { strain } \times 1 / \text { d } \\
10^{9} \text { ufc per strain } \times 2 / d\end{array}$ & [118] \\
\hline
\end{tabular}

after the second week of treatment, in stool frequency while no effect was registered in stool consistency [99].

The microbiota, however, participates in the function of the mucosal barrier against the adhesion of pathogenic bacteria, which is at the base of infectious processes. When this barrier function is altered by chemical agents, antigens, or other stress factors, different types of intestinal disorders can occur, sometimes due to pathogenic bacteria proliferation. Several experimental data suggest that probiotics may contribute to the reinforcement of the activities of the intestinal mucosal barrier, particularly affecting the functionality aspects of intestinal epithelial cells or macrophages (Table 2). Table 4 [100] reports published data of controlled studies on the use of probiotics in prevention and treatment of certain disorders or digestive diseases.

\section{Conclusions}

Some effects of probiotics on normal or pathological functions of the organism are well documented and their use, either alone or in combination with other therapies, may be considered as "evidencebased". However, for other clinical conditions further studies are needed, as the available evidence is not sufficient to demonstrate the efficacy of probiotics.

In general, as discussed in this paper, the effects are "strainspecific" and may not be extended to other probiotics of the same genus or species. More specifically: (1) the influence on the microbiota composition, through probiotic bacteria consumption, may contribute significantly to human health and well-being; (2) the evaluation of the possible beneficial effects must be specific to each combination of strains and not limited to the impacts of different mixed strains; (3) the amount of probiotic bacteria used to induce beneficial effects, as well as the possible effects of the (food) matrix, must be extrapolated from experimental data; the intake must be prolonged over time; (4) in healthy subjects, some probiotics significantly contribute to lessening hive and to the reduction of intestinal discomfort; (5) some probiotics may contrast intestinal pathogens by direct antagonism, e.g. through the production of cytokines, defensins, etc., or by competitive exclusion; (6) some probiotics contribute to the prevention of infectious diarrhea in children; (7) some probiotics are associated with an overall improvement in functional intestinal disorders (bloating, abdominal discomfort, etc.) typical of the irritable bowel syndrome; (8) some probiotics reduce the frequency and severity of necrotizing enterocolitis in premature infants; (9) there is the possibility of using probiotics to accelerate clinical remission in inflammatory bowel disease (IBD) and pouchitis; experimental evidence, however, is not solid; (10) some probiotics, probably due to the stimulation of nonspecific immune pathways, appear to reduce the duration and/or the severity of seasonal viral infections; (11) preliminary, though not univocal, reports suggest that specific strains 
of probiotics can reduce the incidence or some dermatological aspects of allergic diseases in children; (12) foods containing probiotics have proven to be safe both in the healthy population and in patients with some diseases; (13) the complexity of research on probiotics suggests the adoption of tools to assess their effects different from those classically used to evaluate the actions of drugs.

\section{Acknowledgements}

We thank Drs. Claudio Cricelli, Silvio Danese, Gianfranco Delle Fave, Giuseppe Fatati, and Walter Marrocco for critically reviewing the manuscript.

A podcast illustrating this article is available at: http:// mediazone.brighttalk.com/comm/ReedElsevier/6ca03d1e0523616-2250-25192.

\section{References}

[1] Quigley EM. Prebiotics and probiotics; modifying and mining the microbiota. Pharmacol Res 2010;61:213-8.

[2] Laparra JM, Sanz Y. Interactions of gut microbiota with functional food components and nutraceuticals. Pharmacol Res 2010;61:219-25.

[3] Jones BV, Marchesi JR. Accessing the mobile metagenome of the human gut microbiota. Mol Biosyst 2007;3:749-58.

[4] Ley RE, Hamady M, Lozupone C, Turnbaugh PJ, Ramey RR, Bircher JS, et al. Evolution of mammals and their gut microbes. Science 2008;320: 1647-51.

[5] Qin J, Li R, Raes J, Arumugam M, Burgdorf KS, Manichanh C, et al. A human gut microbial gene catalogue established by metagenomic sequencing. Nature 2010;464:59-65.

[6] Jones BV, Sun F, Marchesi JR. Comparative metagenomic analysis of plasmid encoded functions in the human gut microbiome. BMC Genomics 2010;11:46.

[7] Kurokawa K, Itoh T, Kuwahara T, Oshima K, Toh H, Toyoda A, et al. Comparative metagenomics revealed commonly enriched gene sets in human gut microbiomes. DNA Res 2007;14:169-81.

[8] Gill SR, Pop M, Deboy RT, Eckburg PB, Turnbaugh PJ, Samuel BS, et al. Metagenomic analysis of the human distal gut microbiome. Science 2006;312:1355-9.

[9] Hooper LV, Gordon JI. Commensal host-bacterial relationships in the gut. Science $2001 ; 292: 1115-8$.

[10] Backhed F, Ley RE, Sonnenburg JL, Peterson DA, Gordon JI. Host-bacterial mutualism in the human intestine. Science 2005;307:1915-20.

[11] Ley RE, Peterson DA, Gordon JI. Ecological and evolutionary forces shaping microbial diversity in the human intestine. Cell 2006;124:837-48.

[12] Cani PD, Delzenne NM. The role of the gut microbiota in energy metabolism and metabolic disease. Curr Pharm Des 2009;15:1546-58.

[13] Metahit. Metagenomics of the Human Intestinal Tract; 2009. http://www. metahit.eu/fileadmin/Content/Management_Files/Periodic_Report/First periodic_MetaHIT_report-_extended_summary pdf.

[14] Nissle S. Ueber die Grundlagen einer neuen ursaechlichen Bekaempfung der pathologischen Darmflora. Dtsch Med Woch 1916;42:1181-4.

[15] Cummings JH, Macfarlane GT. Role of intestinal bacteria in nutrient metabolism. JPEN J Parenter Enteral Nutr 1997;21:357-65.

[16] Resta SC. Effects of probiotics and commensals on intestinal epithelial physiology: implications for nutrient handling. J Physiol 2009;587:416974.

[17] Lanning DK, Rhee KJ, Knight KL. Intestinal bacteria and development of the B-lymphocyte repertoire. Trends Immunol 2005;26:419-25.

[18] Tsuji M, Suzuki K, Kinoshita K, Fagarasan S. Dynamic interactions between bacteria and immune cells leading to intestinal IgA synthesis. Semin Immunol 2008;20:59-66

[19] Turnbaugh PJ, Hamady M, Yatsunenko T, Cantarel BL, Duncan A, Ley RE, et al. A core gut microbiome in obese and lean twins. Nature 2009;457:480-4.

[20] Ley RE. Obesity and the human microbiome. Curr Opin Gastroenterol 2010;26:5-11.

[21] Falk PG, Hooper LV, Midtvedt T, Gordon JI. Creating and maintaining the gastrointestinal ecosystem: what we know and need to know from gnotobiology. Microbiol Mol Biol Rev 1998;62:1157-70.

[22] Caballero-Franco C, Keller K, De Simone C, Chadee K. The VSL\#3 probiotic formula induces mucin gene expression and secretion in colonic epithelial cells. Am J Physiol Gastrointest Liver Physiol 2007;292:G315-22.

[23] Health and nutritional properties of probiotics in food including powder milk with live lactic acid bacteria; 2001. www.fao.org.

[24] Ministero della Salute Italiano. Linee guida probiotici e prebiotici; 2005.

[25] Guidelines for the evaluation of probiotics in food; 2002. www.fao.org.

[26] Thomas CM, Versalovic J. Probiotics-host communication: modulation of signaling pathways in the intestine. Gut Microbes 2010;1:1-16.

[27] AFFSA. Effets des probiotiques et prébiotiques sur la flore et l'immunité de l'homme adulte; 2005.
[28] EFSA. EFSA Scientific Colloquium Summary Report. OPS: qualified presumption of safety of microorganisms in food and feed; 2004

[29] Barlow S, Chesson A, Collins JD, Dybing E, Flynn A, FruijtierPölloth C, et al. Introduction of a qualified presumption of safety (QPS) approach for assessment of selected microorganisms referred to EFSA. Opinion of the Scientific Committee. EFSA J 2007;587:1-16.

[30] Jansen WT, van der Bruggen JT, Verhoef J, Fluit AC. Bacterial resistance: a sensitive issue complexity of the challenge and containment strategy in Europe. Drug Resist Updat 2006;9:123-33.

[31] Yan F, Polk DB. Probiotic bacterium prevents cytokine-induced apoptosis in intestinal epithelial cells. J Biol Chem 2002;277:50959-65.

[32] Tien MT, Girardin SE, Regnault B, Le Bourhis L, Dillies MA, Coppee JY, et al. Anti-inflammatory effect of Lactobacillus casei on Shigella-infected human intestinal epithelial cells. J Immunol 2006;176:1228-37.

[33] Takeda K, Suzuki T, Shimada SI, Shida K, Nanno M, Okumura K. Interleukin12 is involved in the enhancement of human natural killer cell activity by Lactobacillus casei Shirota. Clin Exp Immunol 2006;146:109-15.

[34] Takeda K, Okumura K. Effects of a fermented milk drink containing Lactobacillus casei strain Shirota on the human NK-cell activity. J Nutr 2007;137:S791-3.

[35] Niers LE, Hoekstra MO, Timmerman HM, van Uden NO, de Graaf PM, Smits $\mathrm{HH}$, et al. Selection of probiotic bacteria for prevention of allergic diseases: immunomodulation of neonatal dendritic cells. Clin Exp Immunol 2007; $149: 344-52$.

[36] Smits HH, Engering A, van der KD, de Jong EC, Schipper K, van Capel TM, et al. Selective probiotic bacteria induce IL-10-producing regulatory T cells in vitro by modulating dendritic cell function through dendritic cell-specific intercellular adhesion molecule 3-grabbing nonintegrin. J Allergy Clin Immunol 2005;115:1260-7.

[37] Iliev ID, Kitazawa H, Shimosato T, Katoh S, Morita H, He F, et al. Strong immunostimulation in murine immune cells by Lactobacillus rhamnosus GG DNA containing novel oligodeoxynucleotide pattern. Cell Microbio 2005;7:403-14

[38] Iliev ID, Tohno M, Kurosaki D, Shimosato T, He F, Hosoda M, et al. Immunostimulatory oligodeoxynucleotide containing TTTCGTTT motif from Lactobacillus rhamnosus GG DNA potentially suppresses OVA-specific IgE production in mice. Scand J Immunol 2008;67:370-6.

[39] Kaur IP, Chopra K, Saini A. Probiotics: potential pharmaceutical applications. Eur J Pharm Sci 2002;15:1-9.

[40] Marco ML, Pavan S, Kleerebezem M. Towards understanding molecular modes of probiotic action. Curr Opin Biotechnol 2006;17:204-10.

[41] Perdigon G, Alvarez S, Medina M, Vintini E, Roux E. Influence of the oral administration of lactic acid bacteria on iga producing cells associated to bronchus. Int J Immunopathol Pharmacol 1999;12:97-102.

[42] Morimoto K, Takeshita T, Nanno M, Tokudome S, Nakayama K. Modulation of natural killer cell activity by supplementation of fermented milk containing Lactobacillus casei in habitual smokers. Prev Med 2005;40:589-94.

[43] Hatakka K, Savilahti E, Ponka A, Meurman JH, Poussa T, Nase L, et al. Effect of long term consumption of probiotic milk on infections in children attending day care centres: double blind, randomised trial. BMJ 2001:322:1327.

[44] Lin JS, Chiu YH, Lin NT, Chu CH, Huang KC, Liao KW, et al. Different effects of probiotic species/strains on infections in preschool children: a double-blind, randomized, controlled study. Vaccine 2009;27:1073-9.

[45] Marseglia GL, Tosca M, Cirillo I, Licari A, Leone M, Marseglia A, et al. Efficacy of Bacillus clausii spores in the prevention of recurrent respiratory infections in children: a pilot study. Ther Clin Risk Manag 2007;3:13-7.

[46] Lu L, Walker WA. Pathologic and physiologic interactions of bacteria with the gastrointestinal epithelium. Am J Clin Nutr 2001;73:S1124-30.

[47] Santosa S, Farnworth E, Jones PJ. Probiotics and their potential health claims. Nutr Rev 2006;64:265-74.

[48] Zuccotti GV, Meneghin F, Raimondi C, Dilillo D, Agostoni C, Riva E, et al. Probiotics in clinical practice: an overview. J Int Med Res 2008;36(Suppl. 1): $1 \mathrm{~A}-53 \mathrm{~A}$.

[49] Davidson GP, Butler RN. Probiotics in pediatric gastrointestinal disorders. Curr Opin Pediatr 2000;12:477-81.

[50] Szajewska H, Setty M, Mrukowicz J, Guandalini S. Probiotics in gastrointestinal diseases in children: hard and not-so-hard evidence of efficacy. J Pediatr Gastroenterol Nutr 2006;42:454-75.

[51] Michail S, Sylvester F, Fuchs G, Issenman R. Clinical efficacy of probiotics: review of the evidence with focus on children. J Pediatr Gastroenterol Nutr 2006:43:550-7.

[52] Guandalini S. Probiotics for children: use in diarrhea. J Clin Gastroenterol 2006;40:244-8

[53] Van Niel CW, Feudtner C, Garrison MM, Christakis DA Lactobacillus therapy for acute infectious diarrhea in children: a meta-analysis. Pediatrics 2002;109:678-84.

[54] Szajewska H, Kotowska M, Mrukowicz JZ, Armanska M, Mikolajczyk W. Efficacy of Lactobacillus GG in prevention of nosocomial diarrhea in infants. Pediatr 2001;138:361-5

[55] Guandalini S, Pensabene L, Zikri MA, Dias JA, Casali LG, Hoekstra H, et al Lactobacillus GG administered in oral rehydration solution to children with acute diarrhea: a multicenter European trial. J Pediatr Gastroenterol Nutr 2000;30:54-60.

[56] Kaila M, Isolauri E, Soppi E, Virtanen E, Laine S, Arvilommi H. Enhancement of the circulating antibody secreting cell response in human diarrhea by a human Lactobacillus strain. Pediatr Res 1992;32:141-4. 
[57] Szymanski H, Pejcz J, Jawien M, Chmielarczyk A, Strus M, Heczko PB. Treatment of acute infectious diarrhoea in infants and children with a mixture of three Lactobacillus rhamnosus strains - a randomized, double-blind, placebocontrolled trial. Aliment Pharmacol Ther 2006;23:247-53.

[58] Oberhelman RA, Gilman RH, Sheen P, Taylor DN, Black RE, Cabrera L, et al. A placebo-controlled trial of Lactobacillus GG to prevent diarrhea in undernourished Peruvian children. J Pediatr 1999;134:15-20.

[59] Mastretta E, Longo P, Laccisaglia A, Balbo L, Russo R, Mazzaccara A, et al Effect of Lactobacillus GG and breast-feeding in the prevention of rotavirus nosocomial infection. J Pediatr Gastroenterol Nutr 2002;35:527-31.

[60] Costa-Ribeiro H, Ribeiro TC, Mattos AP, Valois SS, Neri DA, Almeida P, et al Limitations of probiotic therapy in acute, severe dehydrating diarrhea. J Pediatr Gastroenterol Nutr 2003;36:112-5.

[61] Salazar-Lindo E, Miranda-Langschwager P, Campos-Sanchez M, Chea-Woo E, Sack RB. Lactobacillus casei strain GG in the treatment of infants with acute watery diarrhea: a randomized, double-blind, placebo controlled clinical trial [ISRCTN67363048]. BMC Pediatr 2004;4:18.

[62] Mack DR, Michail S, Wei S, McDougall L, Hollingsworth MA. Probiotics inhibit enteropathogenic E. coli adherence in vitro by inducing intestinal mucin gene expression. Am J Physiol 1999;276:G941-50.

[63] Sarker SA, Sultana S, Fuchs GJ, Alam NH, Azim T, Brussow H, et al. Lactobacillus paracasei strain ST11 has no effect on rotavirus but ameliorates the outcome of nonrotavirus diarrhea in children from Bangladesh. Pediatrics 2005; 116:e221-8.

[64] Guarino A, Lo VA, Canani RB. Probiotics as prevention and treatment for diarrhea. Curr Opin Gastroenterol 2009;25:18-23.

[65] Szajewska H, Ruszczynski M, Radzikowski A. Probiotics in the prevention of antibiotic-associated diarrhea in children: a meta-analysis of randomized controlled trials. J Pediatr 2006;149:367-72.

[66] Cremonini F, Di Caro S, Nista EC, Bartolozzi F, Capelli G, Gasbarrini G, et al Meta-analysis: the effect of probiotic administration on antibiotic-associated diarrhoea. Aliment Pharmacol Ther 2002;16:1461-7.

[67] D'Souza AL, Rajkumar C, Cooke J, Bulpitt CJ. Probiotics in prevention of antibiotic associated diarrhoea: meta-analysis. BMJ 2002;324:1361.

[68] Arvola T, Laiho K, Torkkeli S, Mykkanen H, Salminen S, Maunula L, et al. Prophylactic Lactobacillus GG reduces antibiotic-associated diarrhea in children with respiratory infections: a randomized study. Pediatrics 1999;104:e64.

[69] Lewis SJ, Potts LF, Barry RE. The lack of therapeutic effect of Saccharomyces boulardii in the prevention of antibiotic-related diarrhoea in elderly patients. J Infect 1998;36:171-4.

[70] Castagliuolo I, Riegler MF, Valenick L, LaMont JT, Pothoulakis C. Saccharomyces boulardii protease inhibits the effects of Clostridium difficile toxins A and B in human colonic mucosa. Infect Immun 1999;67:302-7.

[71] McFarland LV. Evidence-based review of probiotics for antibiotic-associated diarrhea and Clostridium difficile infections. Anaerobe 2009;15:274-80.

[72] Claud EC, Walker WA. Hypothesis: inappropriate colonization of the premature intestine can cause neonatal necrotizing enterocolitis. FASEB J 2001;15:1398-403.

[73] Deshpande G, Rao S, Patole S, Bulsara M. Updated meta-analysis of probiotics for preventing necrotizing enterocolitis in preterm neonates. Pediatrics 2010;125:921-30.

[74] Bjorksten B, Naaber P, Sepp E, Mikelsaar M. The intestinal microflora in allergic Estonian and Swedish 2-year-old children. Clin Exp Allergy 1999;29:342-6.

[75] Watanabe S, Narisawa Y, Arase S, Okamatsu H, Ikenaga T, Tajiri Y, et al. Differences in fecal microflora between patients with atopic dermatitis and healthy control subjects. J Allergy Clin Immunol 2003;111:587-91.

[76] Giovannini M, Agostoni C, Riva E, Salvini F, Ruscitto A, Zuccotti GV, et al. A randomized prospective double blind controlled trial on effects of longterm consumption of fermented milk containing Lactobacillus casei in pre-school children with allergic asthma and/or rhinitis. Pediatr Res 2007;62: 215-20.

[77] Abrahamsson TR, Jakobsson T, Bottcher MF, Fredrikson M, Jenmalm MC, Bjorksten B, et al. Probiotics in prevention of IgE-associated eczema: a double-blind, randomized, placebo-controlled trial. J Allergy Clin Immunol 2007;119:1174-80.

[78] Taylor AL, Dunstan JA, Prescott SL. Probiotic supplementation for the first 6 months of life fails to reduce the risk of atopic dermatitis and increases the risk of allergen sensitization in high-risk children: a randomized controlled trial. J Allergy Clin Immunol 2007;119:184-91.

[79] Kukkonen K, Savilahti E, Haahtela T, Juntunen-Backman K, Korpela R, Poussa $\mathrm{T}$, et al. Probiotics and prebiotic galacto-oligosaccharides in the prevention of allergic diseases: a randomized, double-blind, placebo-controlled trial. J Allergy Clin Immunol 2007;119:192-8.

[80] Valsecchi C, Marseglia A, Ricci A, Montagna L, Leone M, Marseglia GL, et al. Probiotics and children: is an integration useful in allergic diseases? Pediatr Med Chir 2008;30:197-203.

[81] Johannsen H, Prescott SL. Practical prebiotics, probiotics and synbiotics for allergists: how useful are they? Clin Exp Allergy 2009;39:1801-14.

[82] Yao TC, Chang CJ, Hsu YH, Huang JL. Probiotics for allergic diseases: realities and myths. Pediatr Allergy Immunol 2010;21:900-19.

[83] Boyle RJ, Bath-Hextall FJ, Leonardi-Bee J, Murrell DF, Tang ML. Probiotics for the treatment of eczema: a systematic review. Clin Exp Allergy 2009;39:1117-27.

[84] van der Aa LB, Heymans HS, van Aalderen WM, Sprikkelman AB. Probiotics and prebiotics in atopic dermatitis: review of the theoretical background and clinical evidence. Pediatr Allergy Immunol 2010;21:e355-67.
[85] Santos JI. Nutrition, infection, and immunocompetence. Infect Dis Clin North Am 1994;8:243-67.

[86] Levander OA. Nutrition and newly emerging viral diseases: an overview. J Nutr 1997;127:S948-50.

[87] Beck MA. Antioxidants and viral infections: host immune response and viral pathogenicity. J Am Coll Nutr 2001;20:S384-8.

[88] Goodwin K, Viboud C, Simonsen L. Antibody response to influenza vaccination in the elderly: a quantitative review. Vaccine 2006;24:1159-69.

[89] Iorio AM, Camilloni B, Basileo M, Neri M, Lepri E, Spighi M. Effects of repeated annual influenza vaccination on antibody responses against unchanged vaccine antigens in elderly frail institutionalized volunteers. Gerontology 2007;53:411-8

[90] Rautava S, Salminen S, Isolauri E. Specific probiotics in reducing the risk of acute infections in infancy - a randomised, double-blind, placebo-controlled study. Br J Nutr 2009;101:1722-6.

[91] Leyer GJ, Li S, Mubasher ME, Reifer C, Ouwehand AC. Probiotic effects on cold and influenza-like symptom incidence and duration in children. Pediatrics 2009:124:e172-9.

[92] de Vrese M, Winkler P, Rautenberg P, Harder T, Noah C, Laue C, et al. Effect of Lactobacillus gasseri PA 16/8, Bifidobacterium longum SP 07/3, B. bifidum MF 20/5 on common cold episodes: a double blind, randomized, controlled trial. Clin Nutr 2005;24:481-91.

[93] de Vrese M, Winkler P, Rautenberg P, Harder T, Noah C, Laue C, et al. Probiotic bacteria reduced duration and severity but not the incidence of common cold episodes in a double blind, randomized, controlled trial. Vaccine 2006;24:6670-4

[94] Pregliasco F, Anselmi G, Fonte L, Giussani F, Schieppati S, Soletti L. A new chance of preventing winter diseases by the administration of synbiotic formulations. J Clin Gastroenterol 2008;42(Suppl. 3, Part 2):S224-33.

[95] Vouloumanou EK, Makris GC, Karageorgopoulos DE, Falagas ME. Probiotics for the prevention of respiratory tract infections: a systematic review. Int J Antimicrob Agents 2009:34:197-210.

[96] Boge T, Remigy M, Vaudaine S, Tanguy J, Bourdet-Sicard R, van der WS. A probiotic fermented dairy drink improves antibody response to influenza vaccination in the elderly in two randomised controlled trials. Vaccine 2009;27:5677-84.

[97] Guillemard E, Tondu F, Lacoin F, Schrezenmeir J. Consumption of a fermented dairy product containing the probiotic Lactobacillus casei DN-114001 reduces the duration of respiratory infections in the elderly in a randomised controlled trial. Br J Nutr 2010;103:58-68.

[98] Chmielewska A, Szajewska H. Systematic review of randomised controlled trials: probiotics for functional constipation. World J Gastroenterol 2010;16:69-75.

[99] Coccorullo P, Strisciuglio C, Martinelli M, Miele E, Greco L, Staiano A. Lactobacillus reuteri (DSM 17938) in infants with functional chronic constipation: a double-blind, randomized, placebo-controlled study. J Pediatr 2010;157:598-602.

[100] Lee MC, Lin LH, Hung KL, Wu HY. Oral bacterial therapy promotes recovery from acute diarrhea in children. Acta Paediatr Taiwan 2001:42:301-5.

[101] Medina M, Izquierdo E, Ennahar S, Sanz Y. Differential immunomodulatory properties of Bifidobacterium logum strains: relevance to probiotic selection and clinical applications. Clin Exp Immunol 2007;150:531-8.

[102] Jacobsen CN, Rosenfeldt Nielsen V, Hayford AE, Moller PL, Michaelsen KF, Paerregaard A, et al. Screening of probiotic activities of forty-seven strains of Lactobacillus spp. by in vitro techniques and evaluation of the colonization ability of five selected strains in humans. Appl Environ Microbiol 1999;65:4949-56.

[103] Cesena C, Morelli L, Alander M, Siljander T, Tuomola E, Salminen S, et al. Lactobacillus crispatus and its nonaggregating mutant in human colonization trials. J Dairy Sci 2001;84:1001-10.

[104] Allen SJ, Okoko B, Martinez E, Gregorio G, Dans LF. Probiotics for treating infectious diarrhoea. Cochrane Database Syst Rev 2004:CD003048.

[105] Sazawal S, Hiremath G, Dhingra U, Malik P, Deb S, Black RE. Efficacy of probiotics in prevention of acute diarrhoea: a meta-analysis of masked, randomised, placebo-controlled trials. Lancet Infect Dis 2006;6:374-82.

[106] Hickson M, D’Souza AL, Muthu N, Rogers TR, Want S, Rajkumar C, et al. Use of probiotic Lactobacillus preparation to prevent diarrhoea associated with antibiotics: randomised double blind placebo controlled trial. BMJ 2007;335:80.

[107] Nista EC, Candelli M, Cremonini F, Cazzato IA, Zocco MA, Franceschi F, et al Bacillus clausii therapy to reduce side-effects of anti-Helicobacter pylori treatment: randomized, double-blind, placebo controlled trial. Aliment Pharmacol Ther 2004;20:1181-8.

[108] Beausoleil M, Fortier N, Guenette S, L'ecuyer A, Savoie M, Franco M, et al. Effect of a fermented milk combining Lactobacillus acidophilus Cl1285 and Lactobacillus casei in the prevention of antibiotic-associated diarrhea: a randomized, double-blind, placebo-controlled trial. Can J Gastroenterol 2007:21:732-6.

[109] Tong JL, Ran ZH, Shen J, Zhang CX, Xiao SD. Meta-analysis: the effect of supplementation with probiotics on eradication rates and adverse events during Helicobacter pylori eradication therapy. Aliment Pharmacol Ther 2007;25:155-68

[110] Sykora J, Valeckova K, Amlerova J, Siala K, Dedek P, Watkins S, et al. Effects of a specially designed fermented milk product containing probiotic Lactobacillus casei DN-114 001 and the eradication of $\mathrm{H}$. pylori in children: a prospective randomized double-blind study. J Clin Gastroenterol 2005;39:692-8. 
[111] Montalto M, Curigliano V, Santoro L, Vastola M, Cammarota G, Manna R, et al. Management and treatment of lactose malabsorption. World J Gastroenterol 2006;12:187-91.

[112] Gawronska A, Dziechciarz P, Horvath A, Szajewska H. A randomized doubleblind placebo-controlled trial of Lactobacillus GG for abdominal pain disorders in children. Aliment Pharmacol Ther 2007;25:177-84.

[113] Kim HJ, Vazquez Roque MI, Camilleri M, Stephens D, Burton DD, Baxter K et al. A randomized controlled trial of a probiotic combination VSL\# 3 and placebo in irritable bowel syndrome with bloating. Neurogastroenterol Motil 2005;17:687-96.

[114] Kajander K, Hatakka K, Poussa T, Farkkila M, Korpela R. A probiotic mixture alleviates symptoms in irritable bowel syndrome patients: a controlled 6month intervention. Aliment Pharmacol Ther 2005;22:387-94.

[115] Guyonnet D, Chassany O, Ducrotte P, Picard C, Mouret M, Mercier CH, et al. Effect of a fermented milk containing Bifidobacterium animalis DN-173 010 on the health-related quality of life and symptoms in irritable bowel syndrome in adults in primary care: a multicentre, randomized, double-blind, controlled trial. Aliment Pharmacol Ther 2007;26: 475-86.

[116] Kruis W, Fric P, Pokrotnieks J, Lukas M, Fixa B, Kascak M, et al. Maintaining remission of ulcerative colitis with the probiotic Escherichia coli Nissle 1917 is as effective as with standard mesalazine. Gut 2004;53:1617-23.

[117] Gionchetti P, Lammers KM, Rizzello F, Campieri M. VSL\#3: an analysis of basic and clinical contributions in probiotic therapeutics. Gastroenterol Clin North Am 2005;34:499-513.

[118] Deshpande G, Rao S, Patole S. Probiotics for prevention of necrotising enterocolitis in preterm neonates with very low birthweight: a systematic review of randomised controlled trials. Lancet 2007;369: 1614-20.

[119] Tao Y, Drabik KA, Waypa TS, Musch MW, Alverdy JC, Schneewind O, et al. Soluble factors from Lactobacillus GG activate MAPKs and induce cytoprotective heat shock proteins in intestinal epithelial cells. Am J Physiol Cell Physiol 2006;290:C1018-30.

[120] Petrof EO, Kojima K, Ropeleski MJ, Musch MW, Tao Y, De Simone C, et al. Probiotics inhibit nuclear factor-kappaB and induce heat shock proteins in colonic epithelial cells through proteasome inhibition. Gastroenterology 2004; $127: 1474-87$.

[121] Neish AS, Gewirtz AT, Zeng H, Young AN, Hobert ME, Karmali V, et al. Prokaryotic regulation of epithelial responses by inhibition of IkappaB-alpha ubiquitination. Science 2000;289:1560-3.

[122] Ruiz PA, Hoffmann M, Szcesny S, Blaut M, Haller D. Innate mechanisms for Bifidobacterium lactis to activate transient pro-inflammatory host responses in intestinal epithelial cells after the colonization of germ-free rats. Immunology 2005; 115:441-50.

[123] Petrof EO, Claud EC, Sun J, Abramova T, Guo Y, Waypa TS, et al Bacteria-free solution derived from Lactobacillus plantarum inhibits multiple NF-kappaB pathways and inhibits proteasome function. Inflamm Bowel Dis 2009;15:1537-47.

[124] Dubuquoy L, Jansson EA, Deeb S, Rakotobe S, Karoui M, Colombel JF, et al. Impaired expression of peroxisome proliferator-activated receptor gamma in ulcerative colitis. Gastroenterology 2003;124:1265-76.

[125] Voltan S, Martines D, Elli M, Brun P, Longo S, Porzionato A, et al. Lactobacillus crispatus M247-derived $\mathrm{H} 2 \mathrm{O} 2$ acts as a signal transducing molecule activating peroxisome proliferator activated receptor-gamma in the intestinal mucosa. Gastroenterology 2008;135:1216-27.

[126] Kelly D, Campbell JI, King TP, Grant G, Jansson EA, Coutts AG, et al. Commensal anaerobic gut bacteria attenuate inflammation by regulating nuclear-cytoplasmic shuttling of PPAR-gamma and RelA. Nat Immunol 2004;5:104-12.

[127] Are A, Aronsson L, Wang S, Greicius G, Lee YK, Gustafsson JA, et al. Enterococcus faecalis from newborn babies regulate endogenous PPARgamma activity and IL-10 levels in colonic epithelial cells. Proc Natl Acad Sci USA 2008;105:1943-8.

[128] Yan F, Cao H, Cover TL, Whitehead R, Washington MK, Polk DB. Soluble proteins produced by probiotic bacteria regulate intestinal epithelial cell survival and growth. Gastroenterology 2007;132:562-75.

[129] Czerucka D, Dahan S, Mograbi B, Rossi B, Rampal P. Saccharomyces boulardii preserves the barrier function and modulates the signal transduction pathway induced in enteropathogenic Escherichia coli-infected T84 cells. Infect Immun 2000;68:5998-6004. 